\title{
La normativa sobre el euskera publicada en 2017
}

Edorta Cobreros Mendazona

DOI: https://doi.org/10.47623/ivap-rvap.110.2018.1.07

\begin{abstract}
Sumario: I. Jurisprudencia. 1. Del Tribunal de Justicia de la Unión Europea. 2. Del Tribunal Constitucional. 3. Del Tribunal Supremo. 4. Del Tribunal Superior de Justicia del País Vasco. 5. Del Tribunal Superior de Justicia de la Comunidad Foral de Navarra. -II. Legislación. 1. Legislación de la Comunidad Autónoma Vasca. 2. Legislación de la Comunidad Foral de Navarra.
\end{abstract}

Como en ocasiones anteriores, analizaremos las aplicaciones judiciales más relevantes en materia lingüística (lato sensu, esto es, aunque no vayan referidas específicamente al euskera, sino que puedan afectar al estatus lingüístico, en general) y, a continuación, recogeremos las actuaciones propiamente normativas que se han producido y que no son muchas, aunque ha habido una cualitativamente destacada en el ámbito de la Comunidad Foral de Navarra, como es la Ley que modifica la Ley del Vascuence. Ahora bien, como la finalidad de estas crónicas anuales es más detectar las novedades producidas que dar cuenta exhaustiva de su contenido, en general únicamente se mencionarán de sucinta manera y al efecto de facilitar mejor su posible consulta.

\section{Jurisprudencia}

\section{Del Tribunal de Justicia de la Unión Europea}

En el ámbito de la Unión Europea, podemos mencionar una sentencia de suTribunal de Justicia. Es la Sentencia de 8 de junio de 2017, as. Sharda Europe, C-293/16, en la que, para la intelección de una Directiva $-y$ ante la diversidad de las versiones lingüísticas -, el Tribunal de Luxemburgo reitera su conocida doctrina interpretativa consistente en que "la formulación utilizada en una de las versiones lingüísticas de una disposición del Derecho de la Unión no puede constituir la única base para la interpretación de dicha disposición y que a esa formulación tampoco se le puede reconocer carácter prioritario a tal efecto frente a otras versiones lingüís- 
ticas. Efectivamente, la necesidad de una aplicación y, por tanto, de una interpretación uniforme de un acto de la Unión exige que éste no sea considerado de manera aislada en una de sus versiones, sino que sea interpretado en función del sistema general y de la finalidad de la normativa en la que se integre» (aptdo. 21).

\section{Del Tribunal Constitucional}

Vamos a mencionar en este apartado cuatro sentencias dictadas en sendos recursos de inconstitucionalidad (interpuestos contra otras tantas leyes catalanas), todas ellas de la misma fecha, que tienen que ver con el estatus del catalán. Cada una merecería un comentario detallado, pero eso nos llevaría muy lejos, razón por la que aquí nos limitaremos a citarlas.

La primera es la Sentencia 86/2017, de 4 de julio, que resuelve un recurso de inconstitucionalidad interpuesto por cincuenta diputados del Partido Popular contra numerosos artículos de la Ley 22/2005, de 29 de diciembre, de la comunicación audiovisual de Cataluña.

La segunda es la Sentencia $87 / 2017$, de 4 de julio, que resuelve otro recurso de inconstitucionalidad, interpuesto por la Defensora del Pueblo contra parte de un artículo de la Ley 10/2010, de 7 de mayo, de acogida de las personas inmigradas y de las regresadas a Cataluña.

La tercera la Sentencia 88/2017, de 4 de julio, que resuelve otro recurso de inconstitucionalidad, interpuesto por el Defensor del Pueblo contra parte un artículo de la Ley 22/2010, de 20 de julio, del Código de Consumo de Cataluña.

La última la Sentencia 89/2017, de 4 de julio, que resuelve un recurso de inconstitucionalidad interpuesto por cincuenta diputados del Partido Popular contra diversos artículos de la Ley 20/2010, de 7 de julio, del cine.

\section{Del Tribunal Supremo}

Referiremos, aquí, sólo la Sentencia de 14 de febrero de 2017, rec. núm. 464/2015, que resuelve un recurso de casación interpuesto por el Abogado del Estado contra la previa Sentencia del Tribunal de Justicia del País Vasco que había desestimado (en rigor, inadmitido) un recurso contencioso-administrativo contra la modificación de la Ordenanza Reguladora de los Requisitos Lingüísticos para los Contratos Administrativos del Ayuntamiento de Lasarte-Oria. Tras una serie de (interesantes) consideraciones sobre la impugnabilidad de disposiciones reglamentarias - en las que ahora no podemos entrar - el Tribunal Supremo man- 
tendrá la constitucionalidad de la norma local impugnada por considerar: A) que no está (doblemente) viciada de incompetencia, pues $1 .^{\circ}$ ) no establece un régimen general y horizontal del régimen de normalización lingüística (que es competencia de la Comunidad Autónoma), sino ante una ordenanza que aborda un ámbito muy concreto; $2 .^{\circ}$ ) ni pretende establecer una suerte de reglamento general de contratación (que es competencia del Estado), sino unos requisitos o condiciones para los licitadores en la contratación de servicios públicos municipales. B) Que no resulta una regulación discriminatoria «pues debería haberse razonado, norma a norma, en qué medida la Ordenanza da lugar a un trato discriminatorio, en qué medida el resultado de su aplicación es la exclusión antijurídica de licitadores, en qué medida las previsiones de esa ordenanza exceden de lo deducible de la legislación autonómica sobre normalización y en qué medida, tomando en consideración servicios concretos y actividades concretas, hay desproporción en las previsiones de la Ordenanza en cuanto a las exigencias del régimen de normalización", extremos todos ellos que no aporta la demanda.

\section{Del Tribunal Superior de Justicia del País Vasco}

Siguiendo la interpretación sostenida en anteriores sentencias (desde 2014), podemos mencionar dos relacionadas con la consideración del euskera a la hora del otorgamiento de diversas ayudas municipales. Así, en primer lugar, tenemos una sentencia del año anterior (pero que no pudo ser recogida en nuestra Crónica relativa a 2016), como es la Sentencia de 18 de noviembre de 2016, rec. núm. 853/2016, referida a una de las bases de la convocatoria de subvenciones a asociaciones vecinales del Ayuntamiento de Hernani - donde se requería que la publicidad (tanto verbal como escrita) que de las actividades subvencionadas hiciera la persona o entidad promotora, dirigida al núcleo de población euskaldun (que parece sería todo el municipio), tanto verbal como escrita, había de hacerse en euskera-, que esta sentencia anula. Por su parte, la Sentencia de 6 de noviembre de 2017, rec. núm. 798/2017, se refiere a las bases reguladoras de la concesión de becas "Sorkuntza» con cargo a los programas del Departamento de Cultura del Ayuntamiento de Azpeitia, de las que ratifica su anulación parcial, en lo que se refiere a la exclusión de los proyectos que se presenten en idioma distinto al euskera.

La Sentencia de 29 de mayo de 2017, rec. núm. 1051/2016, anula parcialmente el Plan de Normalización del Uso del Euskera en el ámbito de actuación de la Diputación Foral de Gipuzkoa y sus organismos autónomos para el periodo 2013-2017. En concreto, los arts. 5 y 11 que impo- 
nían el uso exclusivo del euskera en «ámbitos sociolingüísticos vascófonos" y "zonas sociolingüísticas vascoparlantes», respectivamente; así como el art. 13, que establece el acceso inicial a los contenidos de la web a través de la página de euskera y que el enlace correspondiente a la página en castellano constará «cuando proceda». Por último, se anula también el art. 8, referido a la contratación administrativa por cuanto requiere de los contratistas, y de manera indirecta de su personal, cualesquiera que sean las actividades o servicios objeto de contratación, el cumplimiento de los mismos requisitos lingüísticos a los que la Diputación está sujeta.

\section{Del Tribunal Superior de Justicia de la Comunidad Foral de Navarra}

Procede mencionar un par de sentencias referidas al ámbito educativo, en las que se anulan sendas actuaciones del Gobierno de Navarra y del Organismo Autónomo Escuelas Infantiles Municipales de Pamplona, sobre oferta de plazas de maestro con perfil de euskera y sobre cambio de modelo lingüístico en algunos centros de educación infantil. Se trata de la Sentencia de 20 de octubre de 2017, rec. núm. 112/2016, y de la Sentencia de 15 de noviembre de 2017, rec. 119/2016.

\section{Legislación}

Clasificada por ámbitos (y prescindiendo del estatal, donde no se ha detectado aportación relevante alguna), podemos distinguir las principales innovaciones en la Comunidad Autónoma del País Vasco y en la Foral de Navarra, respectivamente.

\section{Legislación de la Comunidad Autónoma Vasca}

Hemos de mencionar aquí sendos Decretos de la misma fecha y que establecen la estructura orgánica y funcional del Departamento de Educación y del Departamento de Cultura y Política Lingüística. Se trata del Decreto 79/2017, de 11 de abril (BOPV de 21 de abril de 2017) y del Decreto 82/2017, de 11 de abril (BOPV de 21 de abril de 2017), que traen causa de la remodelación departamental realizada por el Lehendakari en noviembre de 2016, tras las elecciones autonómicas.

Asimismo, hay que señalar el Decreto 162/2017, de 30 de mayo (BOPV de 5 de junio de 2017), por el que se regula el Certificado de Calidad en la Gestión Lingüística Bikain y que tiene por finalidad certificar y reconocer 
el nivel de normalización del uso, presencia y gestión lingüística del euskera en el ámbito socioeconómico.

\section{Legislación de la Comunidad Foral de Navarra}

En Navarra sí que se han producido movimientos normativos de entidad. El más importante, por su valor simbólico y por el cambio de política que denota, es la Ley Foral 9/2017, de 27 de junio (BON de 6 de julio de 2017; c.e. BON de 12 de julio de 2017 y BON de 14 de agosto de 2017), por la que se modifica el título y el articulado de la Ley Foral 18/1986, de 15 de diciembre, del Vascuence. Esta Ley contiene tres modificaciones de importancia. La primera, que se sustituye in toto el término "vascuence» por el de "euskera» (art. 1 y disp. adicional). La segunda es una nueva relación de la zonificación lingüística de los municipios, de tal manera que, ahora, un municipio de la zona mixta pasa a incorporarse a la zona vascófona Atez/Atetz) y 44 localidades que pertenecían a la zona no vascófona se incorporan a la zona mixta (arts. 2 y 3). Por último, se establece una habilitación legal expresa para que las entidades locales de Navarra puedan aprobar, en el ámbito de sus competencias, ordenanzas que regulen o fomenten el uso del euskera en su término, sin que puedan contener disposiciones opuestas a lo establecido en esta Ley (art. 5).

También ha de mencionarse la Ley Foral 17/2017, de 27 de diciembre (BON de 30 de diciembre de 2017), reguladora del acceso a la función pública docente, puesto que en un extremo que ha resultado muy discutido, como es que los procesos selectivos se harán con convocatorias distintas y separadas, y con tribunales específicos y distintos, para cada una de las comunidades lingüísticas de la Comunidad Foral de Navarra, para garantizar la ecuanimidad, favorecer a la comunidad escolar y posibilitar igualdad de condiciones a los aspirantes a formar parte de los Cuerpos docentes que no poseen el dominio de ambas lenguas.

A continuación podemos mencionar - sin que quepa aquí resumir su amplio e importante contenido- el Decreto Foral 103/2017, de 15 de noviembre (BON de 30 de noviembre de 2017), por el que se regula el Uso del Euskera en las Administraciones públicas de Navarra, sus organismos públicos y entidades de Derecho Público dependientes.

$\mathrm{Y}$, en el mismo rango reglamentario pero con distinta entidad, tenemos el Decreto Foral 78/2017, de 6 de septiembre (BON de 25 de septiembre de 2017), por el que se modifican los Estatutos del Organismo Autónoma Euskarabidea-Instituto Navarro del Euskera, aprobados por Decreto Foral 130/2015. 